\title{
XII. Alternate current-condensers
}

\section{J. Swinburne}

To cite this article: J. Swinburne (1891) XII. Alternate current-condensers, Philosophical Magazine Series 5, 31:189, 102-108, DOI: 10.1080/14786449108620082

To link to this article: http://dx.doi.org/10.1080/14786449108620082

$$
\text { 曲 Published online: } 08 \text { May } 2009 .
$$

Submit your article to this journal 전

Џll Article views: 2

Q View related articles ¿ 
posing of course sufficient instrumental means. It seems therefore that a specially sensitive electrometer would be doubly effective here, as eliminating the shock and concussion inevitably attendant on a high velocity and a large magnet, which tend to conceal delicate observations.

Hamburg, December 13, 1890.

\section{Alternate Current-Condensers. By J. SwinBuRnE**}

THOUGH condensers have been proposed for various 1 methods of distribution of electrical power, schemes involving the use of them have never developed enough for alternating current-condensers to be made commercially. It is generally assumed that there is no difficulty in making them ; all that is needed is to separate a number of thin plates by means of sheets of insulating material.

The first difficulty is insulation. If a condenser is to take 2000 effective volts, the insulation must be very good. Too great thickness of dielectric cannot be allowed, as that would lessen the capacity, and increase the cost of material. The surface of such a condenser for, say, ten amperes is about a thousand square feet, and the problem of making a thousand square feet of thin insulating material that will safely stand 2000 volts is not easy. I have made samples which, though only a little over a tenth of a millimetre thick, would stand 8000 effective volts for some time before breaking down. When made up into a large condenser, two or three thousand volts would generally break it down in a few hours.

Insulation is not by any means the only difficulty, however ; there is another, which is probably intimately connected with it, and that is absorption of electric power in the dielectric, and consequent heating. It is well known that Leyden jars get hot if charged and discharged frequently; and also that the phenomenon of electric absorption is manifested. When there is absorption, the current out of the condenser is not proportional to the rate of decrease of the electromotive force, and probably the current into it is not proportional to the rate of inerease. This means that the condenser absorbs energy and converts it into heat.

Such questions have been frequently studied in connexion with curves of sines, but it is easier to show the truth of this generally. Let $\mathrm{C}$ be the current, $\mathrm{E}$ the electromotive force,

* Communicated by the Physical Society: read December 12, 1890. 
$\mathrm{K}$ the capacity, and $t$ the time. Then

$$
\mathrm{C}=\mathrm{K} \frac{d \mathrm{E}}{d t}
$$

and the power spent at any instant,

$$
\mathrm{EC}=\mathrm{EK} \frac{d \mathrm{E}}{d t} .
$$

If $e$ is the maximum electromotive force, the work done in charging the condenser is thus

$$
\mathrm{K} \int_{0}^{e} \mathrm{E} d \mathrm{E}=\frac{1}{2} \mathrm{~K} e^{2}
$$

the ordinary expression. On discharging, the work absorbed is

$$
\mathrm{K} \int_{e}^{0} \mathrm{E} d \mathrm{E} \text { or }-\frac{1}{2} \mathrm{~K} e^{2} \text {. }
$$

It is equally easy to show that no power is absorbed in the case of an induction-coil with no hysteresis, without assuming the pressure to vary harmonically.

If $\mathrm{C}$ does not vary as the rate of increase or decrease of $\mathrm{E}$, but is greater on charging and less on discharging, power is absorbed. A hysteresis curve, like those we are accustomed to in iron, can be plotted in the case of a condenser. It has no very close analogy with the case of iron, however.

At first it might seem that absorption might be neglected as too trifling to matter in commercial work. This, however, is not the case. Some condensers about a foot square and an inch thick absorbed over half a horse-power, and soon rose above the temperature of boiling water.

According to Maxwell's theory, the absorption of power is just as easily explained as the time-lag in discharge. Suppose the dielectric is paper soaked in melted paraffin, and suppose the fibres of paper do not insulate and that the paraffin does. When the plates are charged, a fibre running part of the way across the dielectric finds its ends at different potentials; so a current is set up to equalize them. This current means loss of power by heat. It also increases the capacity of the condenser. An increase of the capacity of the condenser when the pressure is increasing, or after it is applied, means increased energy put into the condenser. If the capacity of the condenser were constant, the current into it would be proportional to the rate of increase of the electromotive force, and no power would be absorbed in a period; but if the capacity is increased as the pressure rises and decreased as it 
falls, there is an extra current produced which is not proportional to the rate of increase of the electromotive force, and this supplies the loss in the condenser. The condenser may still show perfect insulation under a direct pressure. According to this theory, absorption is necessarily accompanied by an increase of capacity. This is important in connexion with the electromagnetic theory of light. Absorption would always increase the apparent capacity of a condenser, so that determinations of specific inductive capacity of absorptive dielectrics would come out too high. The dielectrics which come out too high, such as glass, are just those which heat most. The energy absorbed in a given dielectric would be a function of the frequency and the resistance of the conducting parts. It is thus possible that a dielectric might be opaque to light, and diathermanous if the resistance is comparatively low, or transparent to light, but not to dark heat if it is somewhat higher. Similarly a Leyden jar, which absorbs power when connected to an alternating dynamo, may lose little of its energy internally when discharged oscillatorily by a spark. The case of a fibrous imperfect insulator embedded in a perfect insulator is not susceptible of mathematical treatment and was not taken by Maxwell. Mica is perhaps a better example. It is a good insulator, but gets very hot. If a thin plate is put between two sheets of tinfoil, heating soon shows. Here we have tinfoil, then a stratum of air, then mica, which is itself stratified, then air, then tinfoil again. The static attraction presses the foil close against the mica, still there is air. Unless the mica is very thick, the fall of potential between the plates is so rapid that the air breaks down and there is a disruptive discharge between the foil and the mica. This actually occurs; there appears to be a luminous layer of minute blue sparks under the foils, and there is a strong smell of ozone. The discharge under the foils, which is rendered visible by the transparency of the mica, must not be confused with the brush-discharge round the edges of the foil, which differs in appearance. There is considerable heating even when the foil is affixed with paraffin-wax so that there is no air.

Of course mica, being stratified, may consist of alternate sheets of some imperfect conductor and an insulator. It is more difficult to find a reason why glass should heat. At high temperatures it is an electrolyte, and it has no definite solidifying-point, so it may be partially electrolytic at ordinary temperatures. Such an explanation can hardly be applied to such a substance as celluloid. This is a very perfect insulator, at least till it breaks down disruptively, and it 
seems to be homogeneous, and is not hygroscopic, yet it heats considerably.

For commercial condensers the choice of insulating material is limited. Most work has been done on condensers with paper and hydrocarbon insulation. It is difficult to know whether a fault lies in the paper or in the hydrocarbon. The paper is baked at a high temperature, and all temperatures and times of baking have been tried. Paper goes on giving off water till there is nothing but a charred brittle mass left. Many hydrocarbons contain enough water to prevent, for instance, their dissolving rubber. Phosphoric anhydride was used to dry several samples, but seemed to do little good, in fact the crude hydrocarbon was often better. Papers vary astonishingly in their behaviour. Mr. Bourne, who has been working at these things for some months, has tried almost every conceivable way of making condensers. We are just beginning to succeed, but it is more by chance than anything else. We see no reason why one particular kind of paper and one particular kind of hydrocarbon should be better than the others.

Want of homogeneity in the dielectric of a condenser, or of any cable, may lead to disruptive discharges, or breakdowns. For instance, if a dielectric is made up of portions with inductive capacities of 3 and 1 respectively, the parts with a high inductive capacity may arrange themselves so that the "electric displacement" in the other is so great that a disruptive discharge ensues. For instance, if two conducting plates are 3 millim. apart in air, with enough pressure to spark over 2 millim., and if a 2-millim. slab of a dielectric with a specific inductive capacity of 3 is put in, the fall of potential over the air is nearly doubled, and it breaks down and starts a short circuit.

Loss of power in dielectries is not confined to condensers; it may be very serious in cables. A condenser that heated excessively was made like the Deptford mains. The dielectric was very much thinner in proportion to the pressure, and allowing the loss per cubic centimetre to vary as the square of the pressure on its sides, a Deptford main would have a loss of, very ronghly, 7000 watts in the dielectric. It does not follow that this is the exact loss in a Deptford main. Very small differences in the constitution of the dielectric cause large variations in the power wasted. The loss may therefore be very much greater or very much less. Taking the specific inductive capacity of the dielectric as 2 , a sevenmile main has a capacity of 2 microfarads. Wi h 10,000 volts at a frequency of 80 , this takes 10 amperes and 100,000 
"apparent" watts ; 7000 watts is only a small percentage of this.

Another unexpected effect has occurred at Deptford. There is an extraordinary rise of pressure. No authoritatively accurate accounts have been published, so it is difficult to say what has happened; but it is said that when the mains are put on the pressure rises. This is generally explained by saying the mains have capacity, and there is self-induction in the circuit, and the capacity and self-induction have a period which corresponds with the frequency of the dynamo, so that the system sympathises, or acts as a sort of electric resonator, thus giving abnormally bigh pressure. A little consideration will show that this theory is untenable. With such a capacity as that of the Deptford cables the self-induction would have to be enormous.

Let the capacity of the cable be $K$, and the self-induction of the circuit $\mathrm{L}$, in farads and henries or quadrants. Call $\mathrm{E}$ and $\mathrm{C}$ the electromotive force and current respectively. Then

and

$$
\mathrm{E}=\mathrm{L} \frac{d \mathrm{C}}{d t}
$$

$$
\mathrm{C}=-\mathrm{K} \frac{d \mathrm{E}}{d t} \text {. }
$$

Combining these equations,

$$
\frac{d^{2} \mathrm{E}}{d t^{2}}=-\frac{\mathrm{E}}{\mathrm{KL}}
$$

so

and integrating,

$$
\frac{d \mathrm{E}}{d t} \frac{d^{2} \mathrm{E}}{d t^{2}}=-\frac{\mathrm{E}}{\mathrm{KL}} \frac{d \mathrm{E}}{d t}
$$

$$
\left(\frac{d \mathrm{E}}{d t}\right)^{2}=-\frac{1}{\mathrm{KL}}\left(\mathrm{E}^{2}+a\right)
$$

where $a$ is a constant;

or

$$
\frac{d \mathrm{E}}{d t}=-\frac{1}{\sqrt{\overline{\mathrm{KL}}}} \sqrt{ }\left(\mathrm{E}^{2}+a\right) ;
$$

so

and integrating,

$$
\frac{\sqrt{\mathrm{KL}} d \mathrm{E}}{\sqrt{\mathrm{E}^{2}+a}}=-d t,
$$

$$
\sqrt{\mathrm{KL}} \cos ^{-1} \frac{\mathrm{E}}{a}=t,
$$


therefore

and

$$
\mathrm{E} \propto \cos \frac{t}{\sqrt{\mathrm{K}} \overline{\mathrm{L}}}
$$

$$
\mathrm{T}=2 \pi \sqrt{\mathrm{KL}}
$$

When a charged condenser is short-circuited through a circuit with self-induction only, oscillation is produced, the current and pressure both varying harmonically with a frequency of $1 / 2 \pi \sqrt{\mathrm{KL}}$.

In the Deptford case, with a capacity of two microfarads and a period of 0.0125 , the self-induction needed would be half a henry. A choking coil with such a coefficient of self-induction wound to carry 250 amperes, which, I understand, is the load of one main, would take 64,000 volts to get the current through. A transformer only acts on the circuit as a choking coil to the small extent due to the waste induction in it. If built on the lines of commercial transformers, this one would have to be large enough to give an output of hundreds of millions of watts to produce a resonator effect. Moreover, a slight alteration in the speed of the dynamo would throw it "out of tune" with the resonator, so that the effect would disappear. For instance, a 5 per cent. variation of speed would alter the pitch of the dynamo nearly a semitone.

It has been stated that there is a difference of apparent ratio in the Deptford transformer when the main is in circuit; that is to say, that though it generally trunsforms 4 to 1 , when the main is on it tranforms about $4 \frac{1}{2}$ or 5 to 1 . I would suggest this is impossible. There is always a "drop" in transformers due to waste field. In a transformer for 10,000 volts and 250 amperes, if properly designed, it would be well under 1 per cent., probably about one tenth per cent. In order that an oscillatory current should be confined to the "line" side by the waste induction which causes a drop of 1 per cent. and 80 periods per second, the frequency would have to be enormous. Such an oscillatory current would also be excluded from the secondary at the London end. Any effect which does not involve enormous frequencies must show on both sides of the transformers. It might be said that the "drop" of the transformers in the circuit would give enough selfinduction to produce a frequency corresponding to an upper partial of the note of the dynamo. If the dynamo E.M.F. does not vary harmonically, such an effect might be produced, but it would show on the voltmeters at both ends. To give an increase of 15 or 20 per cent. effective pressure, with a total transformer drop of 1 per cent., the frequency would be, 
roughly, 1000, and the effective pressure of the oscillatory component 6000 volts. This would give 72 amperes, and the "skin effect" would absorb a great deal of power.

There is, however, a simpler explanation. The cables have considerable capacity, and take an appreciable current. This "leads" relatively to the electromotive force, so the capacity current passes in the armature-coils when they are just in the position to magnetize the fields more strongly. The fields cannot follow each pulsation of excitation so produced, but are affected by it. Their average excitation is increased. I have tried putting a condenser on one of the old Gramme alternators, which have rather weak fields, and a large number of armature ampere turns. The pressure ran up and burned the voltmeter. I have already gone fully into the action of leading and lagging currents on dynamo fields elsewhere, so the subject need not be pursued here. It would, no doubt, be possible to make an alternator excite itself like a series machine by putting a condenser on the terminals instead of exciting the fields by a direct current machine. Such an arrangement seems scarcely commercial, though interesting.

XIII. On the so-called Meta-Elements. By H. M. Vernon, Scholar of Merton College, Oxford *

D URING the last few years we have had brought before us by several eminent chemists, chief among whom may be mentioned Prof. Crookes and M. Lecoq de Boisbaudran, views on the nature of elements totally different from any that had before existed in the minds of chemists. These views being so totally different from any thing proposed before, were at first received incredulously, and it is only quite recently that at all a large number of chemists have put faith in them. Even as it is, we may, I think, say that belief in what is referred to, namely the so-called meta-elements, is extremely qualified. The existence of these bodies seems to be so much at variance with the known laws of Chemistry, and especially with that which is known as the Periodic Law, that, though positive proof of their existence would seem to be forthcoming, yet it will probably need much more proof than has at present been advanced to render the belief in their existence universal.

The question now comes, whether these "proofs" of the existence of meta-elements are in reality proofs, or whether

* Communicated by the Author. 